\title{
Trabalho em rede. Um olhar sobre a garantia da integralidade dos direitos da criança e do adolescente a partir da política de saúde em Curitiba-PR
}

\author{
Network work. a look at the rights of children completeness warranty and \\ adolescents from the health policy in Curitiba-PR
}

\section{Dione Lolis * \\ Fernanda de Souza Moreira **}

\begin{abstract}
Resumo:
O presente artigo apresenta algumas reflexões resultantes de uma pesquisa que buscou analisar a organização do Trabalho em Rede voltado à garantia da integralidade dos direitos da criança e do adolescente, a partir da Política de Saúde, tendo como lócus o município de Curitiba-PR. A pesquisa, de natureza qualitativa, compreendeu uma revisão bibliográfica, uma pesquisa documental e, sequencialmente, uma pesquisa de campo, onde foram entrevistados treze trabalhadores do território e da gestão inseridos em serviços, órgãos e espaços que compõem o Sistema de Garantia de Direitos da Criança e do Adolescente (SGDCA) no Distrito Sanitário Bairro Novo. Como principais resultados, destaca-se que o trabalho desenvolvido pela Rede de Proteção é um avanço inegável, ainda que a falta de transversalidade, de visão de totalidade, a dificuldade de comunicação e de corresponsabilização de todos os atores envolvidos no SGDCA, assim como a falta de um ator que assuma e exerça o papel de articulador dos demais atores, faz com que esse trabalho não constitua de fato uma Rede Intersetorial.
\end{abstract}

Palavras-chave: Direitos da criança e do adolescente. Rede intersetorial. Integralidade. Saúde.

\begin{abstract}
:
The current study brings a reflection on the service network directed to the guarantee of the integrity of child and teenager's rights through health policy, having as locus Curitiba, capital of Paraná. In order to analyze of the service network directed to the guarantee of the integrity of child and teenager's rights through health policy developed in Curitiba, it was done a bibliographic review, a documentary survey and, subsequently, it were conducted interviews with thirteen workers which composes the Sistema de Garantia de Direitos da Criança e do Adolescente (The System of Guarantee of child and teenager's rights) in Distrito Sanitário Bairro Novo (Sanitary District New Neighborhood). As the main results, it stands out that the work developed by Rede de Proteção (Safety Net) is an undeniable advance, however, there is a lack of mainstreaming, totality view, difficulty of communication and co-responsability of the engaged people in Sistema de Garantia de Direitos da Criança e do adolescente (The System of Guarantee of child and teenager's rights), and also the absence of an engaged
\end{abstract}

\footnotetext{
* Universidade Estadual de Londrina. Mestre em Serviço Social pela PUC-SP e doutora em Sociologia pela Universidade Estadual Paulista Júlio de Mesquita Filho. E-mail: dionelolis@uol.com.br

** Especialista em Saúde da Família e Mestre em Serviço Social e Política Social, UEL, Brasil. E-mail: frefers@hotmail.com
} 
person who takes over and executes the function of guiding the others, results in a work which doesn't constitute a real Rede Intersetorial (Cross-section Net).

Keywords: Rights child and teenager. Cross-section net. Integrity. Health.

\section{Introdução}

A Constituição Federal (CF), promulgada em 1988, traz em seu texto o delineamento legal de direitos e deveres da população brasileira, em uma perspectiva democrática de direitos e valorização plena da cidadania. A Lei Orgânica da Saúde (LOS) Lei $\mathrm{n} \cong \mathrm{8.080}$, de 19 de setembro de 1990, norteada pela equidade, integralidade e universalidade da saúde, institui o Sistema Único de Saúde (SUS). O Decreto Federal no 7508, de 28 de junho de 2011, que regulamenta a LOS, traz a perspectiva de Trabalho em Rede para garantir acesso resolutivo, efetivação do processo de descentralização e redução das desigualdades regionais (BRASIL, 2011a). A Política Nacional de Atenção Integral à Saúde da Criança (PNAISC) considera a intersetorialidade como uma diretriz. Ainda assim, existe um caminho a ser trilhado em prol da proteção integral à criança e ao adolescente e da efetivação dos seus direitos fundamentais previstos no Estatuto da Criança e do Adolescente (ECA) - Lei no 8.069, de 13 de julho de 1990. (BRASIL, 1990).

Em busca da integralidade desses direitos, são necessárias mais do que ações dentro do sistema de saúde. Esta deve ser garantida através do trabalho articulado entre políticas econômicas e sociais (NORONHA; LIMA; MACHADO, 2008). A perspectiva da integralidade - capacidade de enxergar o indivíduo como um ser biopsicossocial, organização das práticas de profissionais e serviços, políticas públicas voltadas ao enfrentamento dos Determinantes Sociais de Saúde (DSS) - no universo de crianças e adolescentes supõe, entre outras, articulações intersetoriais como o Sistema de Garantia de Direitos da Criança e do Adolescente (SGDCA); que é formado pela articulação de diversos atores com o objetivo de garantir a promoção, a defesa e o controle dos direitos de crianças e adolescentes (BRASIL, 2006).

Diante de tais elementos, a questão que surge é: "Quais as fragilidades e desafios do Trabalho em Rede direcionado às crianças e aos adolescentes no Município de Curitiba-PR"1? Esta indagação nos levou à pesquisa com o objetivo principal de analisar a

\footnotetext{
${ }^{1}$ Capital de um dos estados da Região Sul do Brasil, com uma população estimada em 1.879.355 habitantes, dos quais 431.102 estão na faixa etária de 0 a 17 anos (IBGE, 2015).
} 
organização do Trabalho em Rede voltado à garantia da integralidade dos direitos de crianças e adolescentes a partir da Política de Saúde de Curitiba. Como objetivos específicos, elencou-se: conhecer as estratégias utilizadas pela Rede de Saúde de Curitiba para a articulação com os demais serviços e políticas em prol da garantia da integralidade dos direitos de crianças e adolescentes; e identificar a existência de limites para a articulação da Política de Saúde e os demais serviços e políticas voltados para garantia da integralidade de direitos de crianças e adolescentes de Curitiba.

Para o alcance destes objetivos, como metodologia, optou-se por realizar uma pesquisa de natureza qualitativa, de tipo exploratória, desenvolvida a partir de uma pesquisa de campo, registrada em diário de campo, de acordo com Minayo (2013), e que tem seu completo desenvolvimento a partir de uma análise do conteúdo das entrevistas, conforme descreve Bardin (2004). Nesse caminho, realizou-se uma breve revisão bibliográfica sobre o tema, uma pesquisa documental e, por fim, uma pesquisa de campo em que se adotou a técnica de entrevista, a partir de um roteiro semiestruturado, com sujeitos significativos relacionados ao Distrito Sanitário Bairro $\mathrm{Novo}^{2}$, a saber: apoiador central; apoiador de território; diretor do Distrito Sanitário; coordenador de uma Unidade de Saúde (US); representante do Centro de Atendimento Psicossocial Infantil (CAPS-i); representante da maternidade; um conselheiro tutelar; um representante da Política de Educação; e um membro do Conselho Municipal de Direitos da Criança e do Adolescente (CMDCA).

A delimitação do Distrito Sanitário do Bairro Novo de Curitiba como campo de pesquisa deu-se em função do contato prévio com os seus trabalhadores. Quanto aos atores, estes foram intencionalmente elencados para a pesquisa por fazerem parte dos serviços de saúde pertencentes ao território escolhido para o estudo e por integrarem os eixos que compõem o SGDCA, quais sejam: defesa de direitos, promoção dos direitos e controle de efetividade dos direitos. Desta forma, do eixo defesa foi escolhido o Conselho Tutelar; do eixo promoção dos direitos, a Política de Educação; e do eixo controle, o CMDCA.

\footnotetext{
2 O espaço geográfico da SMSC está organizado em três Macrorregionais (Sul, Norte e Leste) e em 10 Distritos Sanitários de Saúde: Bairro Novo, Boqueirão, Boa Vista, Cajuru, Matriz, Pinheirinho, Portão, Santa Felicidade, CIC e Tatuquara. Cada Distrito conta com uma diretoria e três coordenadorias, que são: atenção, gestão e vigilância em saúde (CURITIBA, 2015).
} 
No decorrer da pesquisa, por indicação de alguns destes atores, durante suas entrevistas, outros sujeitos foram envolvidos no estudo: um representante da coordenadoria executiva do CMDCA; um da coordenadoria executiva da Rede de Proteção à Criança e Adolescente em Situação de Risco para a Violência; um da Rede de Proteção local (Distrito do Bairro Novo); e um da Política de Assistência Social.

Com a devida aprovação pelo Comitê de Ética em Pesquisa (parecer consubstanciado do CEP/SMC - CAAE no 44623514.9.0000.5231) as entrevistas foram realizadas entre os dias 10 e 14 de agosto de 2015. Conforme as condições previstas no Termo de Consentimento Livre e Esclarecido, as identidades dos participantes foram mantidas em sigilo, assim, estão identificados como: Saúde - Gestão 1; Saúde - Gestão 2; Saúde - Gestão 3; Saúde - Gestão 4; Saúde - Atenção Especializada; Saúde - Atenção Secundária; Saúde - Atenção Primária 1; Saúde - Atenção Primária 2; Conselho Tutelar; CMDCA 1; CMDCA 2; Educação; Assistência Social.

A análise do conteúdo das entrevistas permitiu chegar a três categorias norteadoras deste estudo: a concepção de Rede; a forma como se dá o processo de Trabalho em Rede; e os desafios e as fragilidades do Trabalho em Rede. Este resultado será apresentado em três momentos distintos, porém complementares: uma exposição breve sobre modelos de gestão e Rede, uma análise sobre o Trabalho em Rede desenvolvido pela Secretaria Municipal de Saúde de Curitiba (SMSC); e uma exposição sobre os desafios e fragilidades da experiência do município.

\section{Estratégias de gestão: trabalho em rede}

Conforme mostram os principais autores consultados, em uma perspectiva histórica, a administração pública pode ser caracterizada pelos modelos de gestão adotados pelos governantes da res publica (coisa do povo) os quais demonstram, inclusive, o nível de participação do cidadão no governo da máquina pública (REK, 2014). Participação que, com o processo de redemocratização que se iniciou no Brasil na década de 1980, "foi concebida na perspectiva do 'controle social' no sentido de os setores organizados da sociedade participarem desde as suas formulações [...] até a definição da alocação de recursos" (CORREIA, 2008). Nesta perspectiva, a administração pública evoluiu através de três modelos básicos: patrimonialista, burocrática e gerencial. "Estas 
três formas se sucedem no tempo, sem que, no entanto, qualquer uma delas seja inteiramente abandonada" (BRASIL, 1995, p. 14-15) 3 .

Para reinventar a gestão de políticas públicas como a Política de Saúde, por exemplo, algumas estratégias de gestão são pensadas e implementadas, inclusive pela SMSC. O Decreto no 7.508 traz para o contexto da Política de Saúde brasileira a necessidade de articulação entre os entes da federação e das secretarias do Ministério da Saúde, a necessidade de diminuir a fragmentação "da agenda estratégica do SUS e as singularidades dos contextos locais" (BRASIL, 2011b, p. 15), com o Trabalho em Rede.

Pensado e praticado de várias formas, o Trabalho em Rede da SMSC, por exemplo, foi adotado em 1998, como uma estratégia de enfrentamento de situações de violação de direitos de crianças e adolescentes. Ao ampliar o olhar para uma melhor compreensão do que é o Trabalho em Rede e até mesmo refletir sobre o que a SMSC propõe, alguns pontos e conceitos precisam ser esclarecidos, para se chegar ao entendimento de que forma o SGDCA se aproxima dessa discussão. E, além disso, identificar limites, que envolvem o trabalho intersetorial, um dos objetivos deste estudo.

Para Sanicola (2008, p. 13), Redes são malhas, muito ou pouco densas, compostas de pontos que se cruzam e promovem "trocas sinérgicas". Elas são permeadas por conflitos, alianças, polarizações e tensões. Podem assumir alguns tipos de orientações metodológicas (orientação terapêutica; organização em Rede; communitycare; e intervenção em Rede), assim como podem desenvolver dois movimentos: do individual para a partilha e da dependência para a autonomia.

Naquele, o indivíduo, ao partilhar alguma necessidade, cria um sentimento de pertencimento à Rede e de uma "identidade individual e comunitária", enfim, cria laços. Ao passo que no segundo movimento há o desenvolvimento da liberdade a partir do amadurecimento do sentimento de pertencimento à Rede, que desperta a capacidade de assumir responsabilidades. As Redes são permeáveis, mas um ou outro movimento prevalece, de acordo com as circunstâncias conjunturais.

Quando extrapola a capacidade resolutiva das redes primárias - familiares, amigos, vizinhos e colegas de trabalho - a partilha se dá por meio das redes secundárias - serviços institucionais (SANICOLA, 2008). De forma complementar, na compreensão de Guará

\footnotetext{
${ }^{3}$ O que Campelo (2010) ratifica ao dizer que não há modelo de administração pública puro.
} 
(1998) existem dois conceitos de Rede: o tradicional e o moderno. O conceito tradicional de Rede está relacionado a um conjunto de serviços similares, organizados de forma hierarquizada e, portanto, atrelado a uma gestão centralizada. Já as Redes modernas "mantêm-se num processo contínuo de busca de legitimação através de fluxos ativos de informação e interação" (GUARÁ, 1998, p.13).

As ditas Redes podem ser classificadas de diversas formas, conforme Guará (1998): redes sociais espontâneas, as quais se dão a partir das relações primárias entres familiares, de vizinhança ou comunidade que se ligam por afinidade, afeto solidariedade e cooperação; redes de serviços público-institucionais, cuja estrutura governamental é direcionada ao atendimento dos direitos positivados através de programas e serviços desenvolvidos pelas políticas públicas; redes sociocomunitárias, organizadas no espaço da comunidade quando as políticas sociais não são efetivadas para atender demandas coletivas; rede de serviços privados, composta por serviços privados; redes sociais movimentalistas, que se constituem de movimentos sociais, os quais se organizam de forma horizontal e promovem a articulação entre seus membros.

Complementar às primeiras definições, no âmbito das políticas públicas, as Redes podem ser setoriais ou intersetoriais. Estas, foco do presente estudo, constituem-se em uma estratégia operacional, que articula políticas públicas no sentido de enfrentar demandas complexas para superar a fragmentação das ações governamentais, e aquelas com uma organização centralizada e hierarquizada de serviços e programas das políticas de saúde, educação, assistência social, entre outras (LAVORATTI, 2013).

A intersetorialidade pode ser entendida "como uma nova lógica de gestão, que transcende um único 'setor' da política social [...], estratégia política de articulação entre setores sociais diversos e especializados". A intersetorialidade é "um instrumento de otimização de saberes; competências e relações sinérgicas, em prol de um objetivo comum; e prática social compartilhada" (PEREIRA, 2014, p. 23). Ela pode ser utilizada frente à necessidade de atuação de forma integrada e articulada para atender as demandas multicausais dos usuários dos diversos serviços (YAZBEK, 2014).

É uma nova forma de gestão de políticas públicas que está necessariamente relacionada ao enfrentamento de situações concretas. Supõe vontade, decisão, que tem como ponto de partida o respeito à diversidade e às particularidades de cada setor ou participante. Envolve, portanto estruturação de elementos de 
gestão que materializem princípios e diretrizes, a criação de espaços comunicativos, a capacidade de negociação e também trabalhar os conflitos para que finalmente se possa chegar, com maior potência, às ações (YAZBEK, 2014, p. 98).

Historicamente não é isso que acontece. As políticas sociais, como educação, saúde e assistência social, apresentam-se setorializadas e desarticuladas. Isto é resultado da forma de gestão centralizadora e hierarquizada a que responde. Cada política, com seu leque de serviços e objetivos, atende ao mesmo usuário; todavia, muitas vezes, isto se dá de forma desconexa das demais políticas (YAZBEK, 2014). Então, trata-se de algo que precisa ser modificado em busca da garantia dos direitos universais, da democracia, da integralidade dos direitos de crianças e adolescentes.

Em Curitiba uma tentativa de mudança em começou há 17 anos. A reflexão a seguir traz elementos do processo de constituição e implementação de um trabalho em Rede.

\section{Trabalho em rede desenvolvido em Curitiba}

A gestão compartilhada entre atores de uma rede, a partir de um planejamento conjunto e a busca por resultados coletivos - com plena participação do Estado, que o Trabalho em Rede representa - possibilita agilidade, melhor utilização de recursos e maior garantia de unidade e continuidade de programas das Redes de Proteção (GUARÁ, 1998).

Nesse sentido, as Secretaria de Saúde e de Educação, juntamente com a Fundação de Ação Social (FAS) e o Instituto Municipal de Administração Pública (IMAP) de Curitiba, elaboraram o Protocolo da Rede de Proteção à Criança e ao Adolescente em Situação de Risco para a Violência para nortear o trabalho de diversos profissionais que compõem a Rede de Proteção desde $2000^{4}$ (CURITIBA, 2008).

Entende-se que desenvolver programas de proteção e prevenção por meio de uma ação integrada e intersetorial de serviços de todas as políticas, assim como instituições governamentais e não governamentais, constitui-se uma estratégia para atuar frente às necessidades de crianças e adolescentes com o objetivo de prevenir e inibir a violência, conforme diz o Protocolo da Rede de Proteção (CURITIBA, 2008).

\footnotetext{
${ }^{4}$ A Rede de Proteção teve início em uma experiência piloto em 1998 (Saúde - Gestão 1).
} 
No Protocolo, ao considerar a doutrina da proteção integral de crianças e adolescentes de que trata o ECA, a necessidade de trabalhar a questão da violência em Curitiba, mediante a sistematização da Rede de Proteção, mostrou-se uma metodologia adequada frente a essa problemática (CURITIBA, 2008).

Dessa forma, a Rede de Proteção se faz de um "conjunto de ações integradas e intersetoriais [...] para prevenir a violência, principalmente doméstica/intrafamiliar e sexual, e proteger a criança e o adolescente" (CURITIBA, 2008, p. 17). O Protocolo enfatiza que é necessário compartilhar objetivos e procedimentos entre todos os atores envolvidos com a Rede de Proteção, estabelecer uma articulação e relações horizontais, para que se construam vínculos de interdependência e complementaridade, o que irá possibilitar a corresponsabilidade entre os pares e, acima de tudo, trabalhar em prol da garantia da atenção integral de crianças e adolescentes. Com isso em mente,

[...] quando nasceu essa ideia de se construir um olhar integrado de proteção às crianças e adolescentes; nasce de uma pesquisa do Instituto Municipal de Pesquisas - que é o IPPUC - uma pesquisa encomendada do Governo Federal, para o atendimento da vítima de violência [...]. Nessa lógica da pesquisa que se pensou: por que não [...] montar uma proposta articulada de enfrentamento à violência? (Saúde-Gestão 1).

Em 1998, portanto, iniciam-se os trabalhos da Rede de Proteção em uma Regional ${ }^{5}$ piloto de Curitiba (Portão), a qual começa a registrar dados que geravam "relatórios mensais em registros manuais" (Saúde - Gestão 1). Disto surge a necessidade de "criar um instrumento onde se registrassem os dados. Por isso que ela [Rede] hoje fica amparada na epidemiologia, apesar de toda interface deste trabalho ser com a assistência [nas unidades de saúde]" (Saúde - Gestão 1). Tal instrumento foi utilizado para a organização dos dados sobre a violência registrados manualmente no Município até 2004 , como lembra um dos atores desta pesquisa,

[...] nós temos um banco oficial como a gente diz, a partir de 2004 [...] de 2004 em diante passa a ser digitado em um sistema EPI, também metodologia do Ministério [da Saúde]. Mas esses dados não eram dados nacionais, eram dados que ficavam aqui. A partir de 2011, o Ministério [da Saúde] organiza todos os sistemas de inclusão de dados, que é o SINAN - Sistema Nacional de Agravos e Notificação - e que passa a obrigar todas as cidades, os municípios, a notificar as suas situações de violência [...] (Saúde - Gestão 1).

\footnotetext{
${ }^{5}$ Espécie de subprefeituras, localizadas em 10 Regiões da cidade, mais especificamente nas "Ruas da Cidadania", que disponibilizam serviços da administração municipal direta e indireta (CURITIBA, 2015).
} 
Desde então passam a existir duas fichas de notificação e dois bancos de dados: municipal e nacional. "Nós tínhamos um banco histórico desse dado e, a partir disso nós começamos a ter que digitar em dois sistemas, para que a gente não perdesse a nossa série histórica de informação" (Saúde - Gestão 1). Embora o trabalho da Rede de Proteção tenha iniciado com foco nas situações que envolvem crianças e adolescentes, "não temos como separar um grupo que só trabalha com criança, um grupo que só trabalha com mulher, [...] então, a gente sempre trabalha com a visão que as pessoas têm de olhar a família" (Saúde-Gestão 1).

Desta forma, o trabalho da Rede de Proteção é direcionado às situações de violência que envolvem idosos, mulheres, pessoas com deficiência ou crianças e adolescentes, cada qual com protocolo específico, mas, como lembra um dos atores, o trabalho é direcionado ao enfrentamento de situações que envolvem violência, seja contra quem for. "Na prática eu [serviço] tenho que estar integrado" (Saúde - Gestão 1). Esses serviços devem atender às demandas relacionadas às crianças e adolescentes, às mulheres, ao idoso e ao deficiente.

A partir das informações geradas pelos dados das fichas de notificação, no que diz respeito à criança e ao adolescente, estabeleceu-se que o objetivo geral da Rede de Proteção de Curitiba seria tornar visível o problema da violência, promover a capacitação de profissionais envolvidos com o atendimento dessa parcela da população, atender vítimas e autores de violências, em busca da superação e reversão da situação, diminuir a sua reincidência e realizar ações preventivas (CURITIBA, 2008).

A Rede de Proteção no Município, conforme um dos atores, está organizada no âmbito local, distrital e central. Em nível central há uma Coordenadoria Executiva da Rede de Proteção composta por um representante da SMSC,

[...] representantes do ensino fundamental; representantes da educação infantil; a gente tem um "namoro" muito próximo [...] com a representante da escola estadual, que representa o setor Curitiba das escolas estaduais ${ }^{6}$; nós temos um conselheiro tutelar; na FAS nós temos um representante da proteção básica, um representante da proteção especial [...] (Saúde - Gestão 1).

\footnotetext{
${ }^{6}$ No ano de 2016 o município firmou um convênio com o ensino privado para atuar, juntamente com demais serviços públicos, frente a questões de violência contra crianças e adolescentes (Saúde - Gestão 1).
} 
Os atores da Coordenadoria promovem capacitações para os distritos e "[...] todas as pessoas que estão envolvidas com a Rede de Proteção, de todas as unidades, de todos os setores, da educação, do Centro de Referência Especializada de Assistência Social (CREAS) e da FAS, são convidadas a participar [...]" (Saúde - Atenção Primária 2). Durante tais capacitações são trabalhados diversos temas, tais como:

[...] identificação de sinais, depois da identificação de sinais para cada público de direito violado [...] vítima de violência sexual, tentativa de suicídio [...] sinais de alerta, o acolhimento, [...] a abordagem aos pais, aos responsáveis; daí a gente tem que trabalhar na questão do acompanhamento para trabalhar resiliência e prevenção [...] (Saúde - Gestão 1).

No âmbito distrital, o trabalho tem como proposta o compartilhamento das experiências de trabalho entre todas as redes locais do Distrito. Mesmo porque "[...] os trabalhos são iguais, só que cada unidade tem o seu perfil de trabalho, sua maneira de trabalhar" (Saúde - Atenção Primária 2). O objetivo do trabalho da Rede de Proteção como um todo é o mesmo, mas cada rede local tem sua forma de conduzir o trabalho no dia a dia. O encontro para troca de experiências é considerado pela SMSC como uma forma de auxiliar outros profissionais em outros espaços.

No espaço local, "[...] o coordenador da Rede, os trabalhadores articulam os componentes da rede local: creche [Centro de Educação Infantil], escola, CREAS, os CRAS [Centro de Referência de Assistência Social]". (Saúde - Gestão 3). Ou,

As demandas que chegam para a Rede de Proteção saem das unidades de saúde, da escola, enfim, dos territórios, na ponta. Então, a partir do momento que o profissional identifica uma criança em risco, um adolescente em risco, seja por questões de violência dentro de casa ou por questões de vulnerabilidade social mesmo, leva a demanda para a Rede de Proteção. Aí é debatido e os encaminhamentos são feitos por lá [...] (Saúde - Gestão 2).

O número de Redes de Proteção local é compatível com o número de USs. Com isso, no Distrito do Bairro Novo, são 12 USs, logo, 12 Redes de Proteção local. Cada serviço que compõe as redes locais tem uma pessoa de referência para participar das capacitações oferecidas pela coordenadoria central, das reuniões da rede distrital e desenvolver o trabalho junto à rede local.

O que desperta o início do trabalho da rede local é o recebimento da notificação. Quando a US a recebe, por exemplo, o trabalhador de referência da Rede de Proteção local vai até o endereço da pessoa que sofreu violência, acompanhado do coordenador da 
unidade "ou com o enfermeiro da área dela ou com o auxiliar, e o agente comunitário [de saúde]" para levantar mais informações e realizar os devidos encaminhamentos (Saúde Gestão 2).

Depois dessa primeira intervenção, as notificações são levadas para discussão com os componentes da rede local (Saúde - Atenção Primária 1). Tais reuniões, no caso da Rede de Proteção do Distrito Bairro Novo, uma das USs, acontecem mensalmente. Nelas são discutidas as notificações de violência que a Rede recebeu, como citou o ator da Saúde - Gestão 2. Em casos mais graves de violência esta mesma rede local pode organizar um fórum para discutir uma situação pontual, de algum usuário específico,

Normalmente, quando é um caso complexo, [...] pode ser um caso que já vem com o tempo, mas pode ser um caso que [...] aconteceu há pouco tempo, mas que não está tendo uma solução. Principalmente a família que não adere às ofertas de serviços que são feitas. Então, pode ser um caso antigo, como pode ser um caso recente (Saúde - Atenção Primária 2).

Ao refletir sobre uma pesquisa solicitada pelo Ministério da Saúde, a SMSC se propõe a utilizar uma estratégia de gestão para enfrentar a complexidade e multicausalidade que a violência doméstica representa. Algo que merece ser destacado, visto que o Trabalho em Rede, estratégia que tem como proposta a articulação de serviços, traz para o debate, dentre outros elementos, a integralidade. Contudo, pelo processo de trabalho aqui descrito, o que é possível perceber é que a Rede de Proteção é a união de serviços e profissionais para capacitação, troca de experiências e discussão de "casos" complexos.

\section{Desafios e fragilidades do trabalho em rede em Curitiba}

Para Yazbek (2014, p. 98), as ações desenvolvidas a partir de uma articulação intersetorial são destinadas "à proteção social, à inclusão e ao enfrentamento das desigualdades sociais identificadas". A intersetorialidade, diz ela, requer à constituição de espaços de comunicação para o estabelecimento de diretrizes e princípios, que servirão para nortear as ações dessa nova forma de gestão das políticas públicas.

Nesse sentido, o que Lavoratti (2013) defende é que as Redes Intersetoriais são mais potentes para responder às expressões da questão social, mesmo porque 
profissionais e instituições de forma isolada têm limites de compreensão e intervenção sobre as mesmas.

Apesar de ter indicação da importância do trabalho intersetorial nos protocolos anteriormente analisados, percebe-se no relato de um dos atores que ainda existe certa dificuldade de implementação dos mesmos,

[...] muitas vezes uma situação chega até você, mas como você não tem noção dessa intersetorialidade, dessa articulação, você se vê incapaz de conseguir encaminhar aquela situação. Mas você também não sabe como encaminhar, você não sabe a outra possibilidade que existe porque você não tem conhecimento. Você não conhece essa articulação, você não conhece os outros serviços que são ofertados, por exemplo (CMDCA 1).

Faz-se necessário o desenvolvimento de competências - comunicativas, relacionais e articuladoras - para a atuação profissional, as quais exigem um "olhar multidimensional e transdisciplinar" para o atendimento das demandas, conforme Carvalho (2010, p. 9). A falta dessas competências resulta em fragmentação da Rede, sobrecarga das Redes primárias e otimização de recursos. Entre outras palavras, são os impedimentos para uma efetiva articulação intersetorial, conforme a maioria dos atores deste estudo aponta.

[...] a rotina de trabalho de cada um desses órgãos acaba fazendo com que ninguém foque esse trabalho intersetorial, porque ele demanda tempo, ele demanda trabalho. E essas equipes, às vezes, não são tão numerosas também. Custam até dar conta do próprio trabalho que têm [...] (CMDCA 1).

A dinamicidade, os interesses, o poder, a vontade, entre outros aspectos, implicados no processo de trabalho intersetorial são percebidos e expostos na opinião de um dos atores sobre o trabalho desenvolvido em Curitiba,

Eu acho que falta [...] essa articulação, essa formação contínua envolvendo todas as políticas; promover essa intersetorialidade a fim de distribuir essas responsabilidades, dizer que a saúde, ela tem a mesma responsabilidade do que a educação, que tem a mesma responsabilidade que a assistência social [...] (CMDCA 1).

Além disso, para o ator da Educação, "seria a valorização daquele profissional" ou a dificuldade em trabalhar de forma mais próxima, não tradicional, como mostra a opinião de um dos atores da saúde,

[...] eu disse: "olha, me passa uma relação do que você tem". Ele disse: "passo, até porque a unidade demora para responder". Então vamos trabalhar juntos? 
Você me passa, eu faço o levantamento, eu vejo - passo para a administração o que a gente pode fazer para tentar agilizar e te dou um retorno. Então eu fiz isso [...], mas eu não vi retorno deles para mim [...] (Saúde - Atenção Primária 1).

A tendência à racionalização apontada por Weber (2004, p. 199) ilumina esta opinião. Segundo ele, no Estado Moderno, com vistas à sua máxima eficiência, a organização burocrática pode viabilizar a otimização de recursos e tem como um dos seus traços a hierarquia. No funcionalismo moderno as atividades, os poderes de mando e a qualificação necessária para o exercício de cada função é devidamente regulamentada; "rege o princípio da hierarquia dos cargos e da sequência de instâncias [...]".

Inojosa (1998) recorre a essa ideia quando trata do período em que as estruturas organizacionais eram moldadas por setores hegemônicos da sociedade e seus interesses, que respeitavam uma escala de especialização e de hierarquia, que representavam a centralização de decisões, a separação entre planejamento e execução de planos, um ambiente excessivamente formal, e a criação de obstáculos para o controle social.

No trabalho realizado pela Rede de Proteção em Curitiba, percebe-se que, apesar de ter uma coordenadoria que promova capacitações para os trabalhadores que fazem parte dela, nem todos os envolvidos no atendimento de pessoas que sofreram violência têm domínio da temática para trabalhar na perspectiva da proteção desses indivíduos ou interesse em desenvolver tal capacidade.

[...] outros setores, outros órgãos que às vezes você faz todo um trabalho aqui na ponta, mas aí ele emperra lá [gestão] porque às vezes chega lá [gestão] $e$ emperra num outro setor. Às vezes não tem um certo conhecimento - emperra aquela situação, não vai para frente. Então era preciso que todos os setores fossem capacitados (Saúde - Atenção Primária 2).

Tais impedimentos vão repercutir em falhas na efetivação da Rede de Proteção e, consequentemente, na negação, violação e/ou negligenciamento de direitos de crianças e adolescentes. Nas articulações intersetoriais é necessário que cada setor ou serviço tenha claro seu papel para conjugar transversalmente "as normativas legais, as políticas e as práticas, sem conformar políticas ou práticas setoriais independentes" (BAPTISTA, 2012, p.188). 
Nas legislações, a intersetorialidade é apresentada de formas diversas, como expusemos. Segundo a PNAISC, ela é considerada uma diretriz na atenção integral à saúde da criança (BRASIL, 2015). Já na LOS esse conceito é tomado no capítulo da organização e direção da gestão no sentido de orientar a criação de comissões para "articular políticas e programas de interesse para a saúde", como alimentação e nutrição, saneamento e meio ambiente, entre outros (BRASIL, 1990b).

O ECA, quando trata da importância de desenvolver ações para prevenir a "ocorrência de ameaça ou violação dos direitos da criança e do adolescente", elenca, dentre outras, "a promoção de espaços intersetoriais locais para a articulação de ações e a elaboração de planos de atuação conjunta focados nas famílias em situação de violência" e a articulação de órgãos governamentais ou não para atuar na promoção, prevenção e defesa dos direitos de crianças e adolescentes (BRASIL, 1990a).

Não por acaso os documentos, que orientam a atenção à saúde da criança e do adolescente de Curitiba, indicam que ações intersetoriais são meios de se prestar o atendimento a esse segmento da população. A Rede de Proteção à criança e ao adolescente em situação de risco para a violência é um exemplo claro disso. $E$, mais que prestar atendimento aos violentados, um dos atores acredita que as ações intersetoriais devem extrapolar o atendimento direto à população,

[...] eu acho que esses colegiados, também, a gente teria que instituir mais intersetorial, em cada distrito, no sentido mais fortalecido também. Eu até cheguei a comentar [...] com a diretora da FAS, lá do Bairro Novo, sobre um planejamento intersetorial no território. Eu acho que também seria um caminho legal. Por exemplo, a partir de casos reais a gente fazer um planejamento intersetorial e o monitoramento do planejamento intersetorial; acho que isso seria uma ação legal. Só que também envolve outras questões e eu ainda não consegui colocar em prática, por outras questões que demandam [..]. (Saúde - Gestão 2 - grifo nosso).

Mais do que atender à demanda do direito violado intersetorialmente, os espaços coletivos podem ser um lugar de construção intersetorial. E, como mencionou um dos atores, pode ser um colegiado intersetorial que pode produzir, inclusive, um planejamento intersetorial no território (Saúde - Gestão 2). Mesmo porque, trabalhar com o direito violado representa uma falha na efetivação dos direitos direcionados às crianças e adolescentes, pois, como diz um dos atores: 
[...] a cada 100 mil habitantes deveria ter um Conselho Tutelar. Se realmente esses serviços existissem, não precisaria ter tantos Conselhos Tutelares [...]. Então, é sinal de que eles não funcionam, porque se eles funcionassem não teriam direitos violados (Conselho Tutelar).

Na opinião do ator Conselho Tutelar é possível perceber a negligência do Estado tendência à privatização, redução da máquina pública - saídas eficientes e ágeis, segundo os defensores do neoliberalismo (RIZZOTTO, 2008). No Brasil a tentativa tardia de implementação do Estado de Bem-Estar Social foi barrada pela lógica neoliberal, que encontrou nas bases conservadoras o cenário ideal para submeter os direitos constitucionalmente garantidos à lógica do ajuste fiscal. As políticas sociais foram descentralizadas (transferência de responsabilidades e financiamento a todos os entes da federação); privatizadas (transferência para instituições privadas); e, por fim, a seletividade e a focalização representam um direcionamento de ações ao pobre do mais pobre, o que significa uma reorganização e uma redução dos papéis do Estado (BEHRING; BOSQUETTI, 2008).

Além do trabalho realizado frente aos direitos já violados, a Rede de Proteção entende que um trabalho de prevenção de situações de violência deve ser realizado paralelamente. Contudo,

Prevenção que é o grande desafio desse trabalho. Montar ações preventivas. Se eu tenho uma área que eu tenho um grande índice de gravidez na adolescência, de maus-tratos de uma determinada faixa etária, por que não fazermos movimentos de prevenção? Prevenção não é aquele grande, megaevento. Mas é prevenção diária, é contínua. Como é que a escola pode montar seu projeto político pedagógico? Como que a saúde pode montar dentro da sua área de promoção à saúde? [...] (Saúde - Gestão 1).

Apesar de todas as dificuldades elencadas há um trabalho muito importante desenvolvido pela Rede de Proteção de Curitiba. Pensado e executado pelas políticas de saúde, educação e assistência social, juntamente com o Conselho Tutelar, diante da complexidade do enfrentamento à violência, tais políticas e serviços demandam constantemente atuação de outros sujeitos.

Esta Rede, portanto, é parte de um sistema ampliado; ela:

Integra o Sistema Municipal de Garantias de Direitos/SGD, no eixo de Promoção dos direitos humanos de crianças e adolescentes. Ao mesmo tempo, esta "Rede" (CN) dialoga com outras redes que compõem o SGD estadual (secretarias estaduais de saúde e segurança pública e órgãos judiciais), e 
consequentemente se articula com os outros eixos do referido Sistema (Defesa e Controle), para poder atingir seus objetivos de proteção das vítimas de violência (LAVORATTI, 2013, p. 164-165 - grifo nosso).

Institucionalizado pela Resolução no 113, de 19 de abril de 2006, do Conselho Nacional dos Direitos da Criança e do Adolescente (CONANDA), o SGDCA, constitui-se,

[...] na articulação e integração das instâncias públicas governamentais e da sociedade civil, na aplicação de instrumentos normativos e no funcionamento dos mecanismos de promoção, defesa e controle para a efetivação dos direitos humanos da criança e do adolescente, nos níveis Federal, Estadual, Distrital e Municipal (BRASIL, 2006).

Seus atores estão organizados em três eixos ${ }^{7}$; 1) Eixo Defesa: Poder Judiciário, Ministério Público, Conselho Tutelar, Segurança Pública; 2) Eixo Promoção: Conselho Municipal de Direito da Criança e do Adolescente (CMDCA), Poder Executivo (políticas públicas), outros membros da Administração Pública; 3) Eixo Controle: sociedade civil organizada, fóruns, CMDCA, conselhos setoriais. Os envolvidos nos três eixos precisam ter claro o papel de cada ator para que o trabalho se dê de forma coordenada e integrada (DIGIÁCOMO, 2014).

Desenvolver um trabalho de forma cooperativa com tais atores, um Trabalho em Rede, produz novos conhecimentos. Mais do que isso, "o que agrega valor à proposta de uma rede de proteção social é a boa definição de seu foco de atuação. A existência de um objetivo bem definido pode ser decisiva para o sucesso dessa rede" (GONÇALVES; GUARÁ, 2010, p. 17). A “perspectiva de sistema [...] precisa ser concebida e articulada como uma totalidade complexa, composta por uma trama sociopolítica operativa: um sistema que agrega conjuntos de sistemas espacial e setorialmente diferenciados" (BAPTISTA, 2012, p. 10-11).

Embora as estruturas e processos das políticas sociais sejam mais formais, quando se fala de trabalho em rede, são as relações sociais entre agentes públicos e outros atores que pertencem a esferas diferentes do Sistema de Garantia de Direitos da Criança e do Adolescente - SGDCA que dão efetividade e eficácia à intervenção. Não é apenas a organização e o tipo de troca que define a qualidade das relações, e sim a clara intenção dos participantes em atuar cooperativamente por um objetivo comum (GUARÁ, 1998, p. 42).

\footnotetext{
${ }^{7}$ Conforme Baptista (2012), pautada na dinâmica histórica do SGDCA, existem mais dois eixos do sistema: instituição do direito e da sua disseminação.
} 
As ações, programas e serviços dessa "engrenagem", desses atores do SGDCA, constituem a Rede de Proteção à Criança e ao Adolescente, cujo objetivo é a proteção integral desses sujeitos (PARANÁ, 2012).

\begin{abstract}
Assim sendo, a "Rede de Proteção" pressupõe a atuação dos diversos componentes do "Sistema de Garantias" de forma articulada, ordenada e integrada, de modo a permitir o rápido e eficaz atendimento das necessidades básicas das crianças, adolescentes e suas respectivas famílias como um todo, evitando assim a omissão ou a superposição de ações (PARANÁ, 2012, p.4).
\end{abstract}

Dessa forma, existe o SGDCA, com suas ações, programas e serviços que, conforme o Ministério Público do Paraná (MP/PR), compõem a denominada Rede de Proteção à Criança e ao Adolescente (PARANÁ, 2012) e a Rede de Proteção à Criança e ao Adolescente em Situação de Risco para Violência, um programa desenvolvido e executado pela SMSC. Esta desenvolve seu trabalho a partir de um disparador específico que é a situação de violência (CURITIBA, 2008), ao contrário daquele que tem previsão legal de trabalhar medidas de proteção socioeducativas para crianças, adolescentes, pais ou responsável, combate à evasão escolar, prevenção e tratamento de crianças e adolescentes usuários de substâncias psicoativas, egressos de unidade de internação, entre outros que o ECA prevê (PARANÁ, 2012).

Para tanto, a Rede de Proteção, com a atuação de todos os componentes do SGDCA, segundo o MP/PR, precisa articular ações intersetoriais, cujo papel de articulador é apontado para o Poder Executivo, juntamente com o CMDCA. Isso não isenta a colaboração de todos os atores do sistema em prol desse trabalho conjunto (PARANÁ, 2012). Isso vai ao encontro do que as normativas legais e documentos apresentados nesse estudo defendem, inclusive o Protocolo da Rede de Proteção à Criança e ao Adolescente em Situação de Risco para a Violência de Curitiba - envolver profissionais e instituições diversos, desenvolver um contínuo Trabalho em Rede (CURITIBA, 2008).

No caso específico de Curitiba, conforme um dos atores, a articulação da Rede de Proteção precisa ser repensada.

[...] sempre falta um articulador, creio eu [...]. Falta alguém, alguém. Eu acho que essa assessoria de Direitos Humanos ${ }^{8}$ faria um trabalho brilhante em

\footnotetext{
8 Organizada em agosto de 2014 para dar início à Comissão Municipal de Direitos Humanos de Curitiba (CURITIBA, 2015).
} 
relação a essa questão. Alguém para focar, para articular, uma pessoa que convoque. Porque se deixar para a Assistência [social], [ela] sozinha não consegue resolver. Saúde sozinha também não. Então alguém que foque mesmo a questão do Sistema de Garantia de Direitos que vai conseguir fortalecer isso (CMDCA 1).

A doutrina da proteção integral que a CF, denominada constituição cidadã do Estado Democrático de Direito, e o ECA trazem deve ser o objetivo maior de todo o trabalho que envolve crianças e adolescentes. Assegurar que todas as crianças e adolescentes tenham seus direitos garantidos constitui-se na árdua tarefa de executores e gestores das políticas públicas, da sociedade, de entidades e de trabalhadores, que têm em pauta a infância e a juventude.

\section{Considerações finais}

Ao traçar como objeto e estudo a rede de serviços voltados à garantia da integralidade de direitos da criança e do adolescente, a partir da Política de Saúde em Curitiba, optou-se por analisar o processo de constituição e implementação do Trabalho em Rede. Com isso, entende-se que promover o cuidado em saúde sem considerar o princípio da integralidade torna-se tarefa impossível. As necessidades de saúde dos indivíduos são multifacetadas, o que implica o envolvimento de conhecimentos, serviços e profissionais diversos em torno do cuidado em saúde.

A Secretaria de Saúde de Curitiba trouxe aspectos históricos valiosos para o desenvolvimento da Política de Saúde no município. O entendimento sobre a necessidade de trabalhar intersetorialmente, explícito em documentos, sites oficiais e protocolos clínicos, são avanços que merecem destaque. Tal iniciativa e forma de pensar suas ações estão no mesmo patamar de importância do trabalho da Rede de Proteção. Por 17 anos essa Secretaria, diante do crescente número de ocorrências de violência contra crianças e adolescentes em um primeiro momento e, posteriormente, contra mulheres, idosos e deficientes, desenvolve um trabalho juntamente com outras políticas e órgãos. Esta postura demonstra um entendimento sobre a necessidade de agregar conhecimento, políticas e órgãos no enfrentamento à violência.

Contudo, ainda existem alguns pontos a serem trabalhados. Exemplo disso é a sobrecarga de trabalho determinado pelo pequeno número de profissionais na Rede e a 
dificuldade de atingir todos os profissionais no processo de capacitação. E mais preocupante ainda é verificar que não são todos os trabalhadores que entendem que a violência é, sim, uma demanda importante e de um conjunto de trabalhadores, não de um específico, e saber que o trabalho da Rede de Proteção é direcionado, na maior parte do tempo, para trabalhar situações de direito já violado em detrimento das ações de prevenção.

Faltam, ainda, "capacidade" de comunicação, articulação, transversalidade nas normativas, planejamento e um articulador dessa Rede. Ou seja, o SGDCA traz para a cena um trabalho ainda fragilizado, que não consegue, de fato e totalmente, pautar sua prática na integralidade. Sem a capacidade de comunicação efetiva, de trabalhar transversalmente, de traçar um objetivo comum a todos os envolvidos no cuidado de crianças e adolescentes, a Rede de Proteção de Curitiba não se constitui como uma rede intersetorial.

Em síntese, os atores identificam as seguintes dificuldades na Rede: desconhecimento dos serviços; falta primazia na intersetorialidade; ênfase no encaminhamento em detrimento do compartilhamento; falta de corresponsabilização dos atores; demanda focalizada e unicausal; distanciamento entre a gestão municipal e os serviços do território; capacitação que não atinge todos os trabalhadores; falta de planejamento intersetorial.

Além de rever os pontos frágeis identificados pelos atores deste estudo, seja em Curitiba ou em outro município, entende-se que o Trabalho em Rede requer pactuação constante e educação permanente para garantir a integralidade. Mais que desenvolver ações intersetoriais por uma determinação da legislação vigente, o trabalho conjunto entre diversos serviços, órgãos e políticas, por envolver diversos saberes e profissionais, em um contexto que sofre constantes transformações, precisa ser pensado e pactuado durante todo o seu processo. Mais do que propiciar a capacitação aos trabalhadores, fazse necessária a difusão de conhecimentos a partir da realidade vivida. O processo de mudança necessita de foco na problematização do cotidiano.

Enfim, é essencial recuperar o significado de integralidade, o qual, apesar de incorporado às legislações brasileiras e documentos diversos, por motivos variados, algumas vezes fica perdido ou esquecido na rotina volumosa de trabalho dos serviços da 
Rede. Rememorar a letra da lei se faz necessário, mesmo porque tratar de integralidade é tratar de Direitos Humanos e da recusa do autoritarismo.

\section{Referências}

BAPTISTA, M.V. Algumas reflexões sobre o sistema de garantia de direitos. Revista Serviço Social e Sociedade, São Paulo, n. 109, p. 179-199, jan./mar. 2012.

BARDIN, L. Análise de conteúdo. 3. ed. Lisboa: Ed. 70, 2004.

BEHRING, E.R.; BOSCHETTI, I. Política social: fundamentos e história. 5. ed. São Paulo: Cortez, 2008.

BRASIL. Câmara da Reforma do Estado. Plano diretor da reforma do aparelho do Estado. Brasília, 1995. Disponível em: <http://www.bresserpereira.org.br/ documents/mare/planodiretor/planodiretor.pdf>. Acesso em: 1 jul. 2016.

BRASIL. Constituição (1988). Constituição da República Federativa do Brasil. 1988. Disponível em: <http://www.planalto.gov.br/ccivil_03/Constituicao/Constitui\% C3\%A7ao.htm>. Acesso em: 14 dez. 2014.

BRASIL. Decreto no 7.508, de 28 de junho de 2011. Regulamenta a Lei no 8.080, de 19 de setembro de 1990, para dispor sobre a organização do Sistema Único de Saúde - SUS, o planejamento [...], e dá outras providências. 2011a. Diário Oficial da União, Brasília, DF, 28 jun. 2011. Disponível em: <http://www.planalto.gov.br/ccivil_03/_ato20112014/2011/decreto/D7508.htm>. Acesso em: 19 maio 2016.

BRASIL. Lei no 8.069, de 13 de julho de 1990. Dispõe sobre o Estatuto da Criança e do Adolescente e dá outras providências. Diário Oficial da União, Brasília, DF, 13 jul. 1990a. Disponível em: <http://www.planalto.gov.br/ccivil_03/leis/L8069.htm>. Acesso em: 26 mar. 2015.

BRASIL. Lei $n$ ㅇ 8.080, de 19 de setembro de 1990. Dispõe sobre as condições para a promoção, proteção e recuperação da saúde, a organização e o funcionamento dos serviços correspondentes e dá outras providências. Diário Oficial da União, Brasília, DF, 20 set. 1990b. Disponível em: <http://www.planalto.gov.br/ccivil_03/leis/L8080.htm>. Acesso em: 1 maio 2015.

BRASIL. Ministério da Saúde. Caderno de referência para o processo de formação de profissionais do apoio institucional integrado do Ministério da Saúde: QualiSUS-Rede. Brasília, 2011b.

BRASIL. Portaria no 1.130, de 5 de agosto de 2015. Institui a Política Nacional de Atenção Integral à Saúde da Criança (PNAISC) no âmbito do Sistema Único de Saúde (SUS). Diário Oficial da União, Brasília, DF, 6 ago. 2015. Disponível em: 
<http://www.prosaude.org.br/2013/legislacao_2013/Legislacao_Textos/Portaria\%20N.\% 201130\%20_\%2005082015.pdf>. Acesso em: 29 nov. 2015.

BRASIL. Secretaria Especial dos Direitos Humanos Conselho Nacional dos Direitos da Criança e do Adolescente. Resolução no 113, de 19 de abril de 2006. Dispõe sobre os parâmetros para a institucionalização e fortalecimento do Sistema de Garantia dos Direitos da Criança e do Adolescente. Brasília, DF, 19 abr. 2006. Disponível em: $<$ http://dh.sdh.gov.br/download/resolucoes-conanda/res-113.pdf>. Acesso em: 22 mar. 2016.

CAMPELO, G.S.B. A administração pública no Brasil: ciclos entre patrimonialismo, burocracia e gerencialismo, uma simbiose de modelos. 2010. Disponível em: <https://periodicos.fundaj.gov.br/CIC/article/viewFile/871/592>. Acesso em: 12 jan. 2017.

CARVALHO, M.C.B. Introdução. In: GUARÁ, I.M.R. (Coord.). Rede de proteção. São Paulo: Associação Fazendo História, 2010. p.8-9.

CORREIA, M.V.C. Controle social. In: PEREIRA, I.B.; LIMA, J.C.F. Dicionário da educação profissional em saúde. 2. ed. Rio de Janeiro: EPSJV, 2008.

CURITIBA. Prefeitura Municipal. Portal da Prefeitura de Curitiba. 2015. Disponível em: <http://www.curitiba.pr.gov.br/>. Acesso em: 29 nov. 2015.

CURITIBA. Secretaria Municipal da Saúde. Protocolo da Rede de Proteção à criança e ao adolescente em situação de risco para a violência. Curitiba, 2008.

DIGIÁCOMO, M.J. O sistema de garantias de direitos da criança e do adolescente e o desafio do trabalho em "rede". Disponível em: <http://www.mp.pr.gov.br/arquivos/ File/Sistema_Garantias_ECA_na_Escola.pdf>. Acesso em: 1 maio 2014.

GONÇALVES, A.S.; GUARÁ, I.M.R. Redes de proteção social na comunidade. In: GUARÁ, I.M.R. (Coord.). Rede de proteção. São Paulo: Associação Fazendo História, 2010.

GUARÁ, I.M.R. Gestão municipal dos serviços de atenção à criança e ao adolescente. São Paulo: IEE/PUC-SP; Brasília: SAS/MPAS, 1998.

IBGE. Cidades. Disponível em: <http://www.cidades.ibge.gov.br/xtras/perfil.php? lang $=\&$ codmun=410690 $>$. Acesso em: 29 nov. 2015.

INOJOSA, R.M. Intersetorialidade e a configuração de um novo paradigma organizacional. Revista de Administração Pública, Rio de Janeiro, v. 2, n. 32, p. 35-48, mar./abr. 1998.

LAVORATTI, C. Tecendo a rede de proteção: desafios do enfrentamento intersetorial à violência intrafamiliar contra crianças e adolescentes no município de Curitiba/PR. 2013. 318 f. Tese (Doutorado em Sociologia) - Universidade Federal do Paraná, Curitiba, 2013.

MINAYO, M.C.S. O desafio do conhecimento: pesquisa qualitativa em saúde. 13. ed. São Paulo: Hucitec, 2013. 
NORONHA, J.C.; LIMA, L.D.; MACHADO, C.V. O sistema único de saúde - SUS. In: GIOVANELLA, L. (Org.). Políticas e sistemas de saúde no Brasil. Rio de Janeiro: Fiocruz, 2008. p. 435-472.

PARANÁ. Ministério Público. Manual que respeita a criança: manual de orientação aos gestores municipais. Curitiba, 2012.

PEREIRA, P.A.P. A intersetorialidade das políticas sociais na perspectiva dialética. In: MONNERAT, G.L.; ALMEIDA, N.L.T.; SOUZA, R.G. (Org.). A intersetorialidade na agenda das políticas sociais. Campinas: Papel Social, 2014. p. 21-39.

REK, M. Os modelos de administração pública e reflexos à qualidade na gestão administrativa brasileira. 2014. Disponível em: <http://www.ambito-juridico.com.br/ site/?n_link=revista_artigos_leitura\&artigo_id=14742>. Acesso em: 25 jun. 2016.

RIZZOTTO, M.L.F. Neoliberalismo e saúde. In: PEREIRA, I.B.; LIMA, J.C.F. Dicionário da educação profissional em saúde. 2. ed. Rio de Janeiro: EPSJV, 2008.

SANICOLA, L. As dinâmicas da rede e o trabalho social. Tradução Durval Cordas. São Paulo: Veras, 2008.

YAZBEK, M.C. Sistemas de proteção social, intersetorialidade e integração de políticas sociais. In: MONNERAT, G.L.; ALMEIDA, N.L.T.; SOUZA, R.G. (Org.). A intersetorialidade na agenda das políticas sociais. Campinas: Papel Social, 2014. p. 77-103.

WEBER, M. Economia e sociedade: fundamentos da sociologia compreensiva. Tradução Regis Barbosa e Karen E. Barbosa. São Paulo: Imprensa Oficial do Estado de São Paulo, 2004. v. 2. 